\title{
Should physicians go out of the way to differentiate between acute hepatitis $B$ and acute exacerbation of chronic hepatitis B?
}

\author{
Hyun Woong Lee \\ Department of Internal Medicine, Gangnam Severance Hospital, Yonsei University College of Medicine, Seoul, Korea
}

Keywords: Hepatitis B; Chronic hepatitis; Antibodies

See Article on Page 187

The article by Lall et al.' published in Clinical and Molecular Hepatology fuels the discussion on differentiating laboratory markers between acute hepatitis B (AHB) and acute exacerbation of chronic hepatitis $B$ (CHB-AE). This small retrospective study, which included 172 patients with AHB ( $n=89)$ or CHB-AE $(n=83)$, had numerous strengths such as relevantly good follow-up, baseline assessment of IgM anti-HBc level, prothrombin time (PT), HBV DNA level, as well as qHBsAg and HBeAg values. The median cutoff ratio of IgM anti-HBC was significantly higher in AHB (30.44) than in CHB-AE (8.63) $(P<0.01)$. The mean PT international normalized ratio (INR) was significantly greater in CHB-AE $(1.88 \pm 1.24)$ compared to AHB $(1.62 \pm 0.17)$. However, such findings were not new, and they must be taken with caution for several reasons.

In clinical practice, the similarities between AHB and CHB-AE in both clinical and laboratory context make it difficult to distinguish between the two clinical entities. ${ }^{2}$ Nevertheless, differentiating between the two entities is important, as they have different prognoses and therapeutic strategies. ${ }^{3,4}$ Most patients with AHB recover spontaneously, and treatment may be required only in a small number of patients who progress to fulminant hepatitis. On the other hand, patients with CHB-AE generally need antiviral therapy, since hepatic decompensation may be developed in patients with cirrhosis, especially. ${ }^{5,6}$ According to this study, a value of 20.5 for signal cut-off of IgM anti-HBC and 1.27 INR can be used to differentiate between AHB and CHB-AE. The evaluation of IgM anti-HBc levels seems to be an interesting strategy for differentiating the two clinical entities. Likewise, some reports have proposed that IgM anti-HBc levels should be reconsidered to define $A H B{ }^{7,8}$ However, the diversity of reference values suggested from various studies is remarkable. These findings make it difficult to establish a standard reference value as the cut-off level. ${ }^{8-12} \mathrm{Un}$ fortunately, as the author mentioned, IgM anti-HBc test was not a quantitative assay but a semiquantitative assay in this study. Therefore, the lack of prospective study about the standardization

\begin{abstract}
Abbreviations:
$A H B$, acute hepatitis $B$; ALT, alanine aminotransferase; $C H B-A E$, acute exacerbation of chronic hepatitis $B ; H B V$, hepatitis $B$ virus; INR, international normalized ratio; $\mathrm{PT}$, prothrombin time
\end{abstract}

\section{Corresponding author: Hyun Woong Lee}

Department of Internal Medicine, Gangnam Severance Hospital, Yonsei University College of Medicine, 211 Eonju-ro, Gangnam-gu, Seoul 06273, Korea

Tel: +82-2-2019-3315, Fax: +82-2-3463-3882

E-mail:Ihwdoc@yuhs.ac

https://orcid.org/0000-0002-6958-3035 
of quantitative assays and any valid clinical threshold would make the use of this marker quite unreliable. ${ }^{13}$ Moreover, the presence of $\operatorname{IgM}$ anti-HBC, which is associated with $A H B$, is necessary but not sufficient to diagnose AHB. IgM anti-HBC can be detected during episodes of CHB-AE. It may be the result of inflammation and liver cell injury during flare-ups of hepatitis, with consequent release of high concentrations of the nucleocapsid protein. These proteins lead to the activation of pre-existing plasma cells which are released into the circulation, and eventually contribute to the secretion of IgM anti-HBc during acute exacerbation. ${ }^{14}$ It can also lead to a misdiagnosis of AHB.

In addition, PT is not effective in differentiating between two entities, due to its short half-life and data obtained only at a onetime point. In particular, the proportion of cirrhosis was more than $70 \%$ in CHB-AE. PT is affected by the presence of cirrhosis. Therefore, PT seems to have poor sensitivity and specificity to discriminate between two entities.

Among other diagnosis tools, the avidity index of IgG anti-HBC is defined as the strength of $\lg G$ binding to antigenic epitopes of hepatitis $B$ virus (HBV). ${ }^{15}$ This increases as IgG matures. Therefore, the low avidity index of $\lg G$ anti-HBC is an indicator of $A H B$, and high avidity index refers to CHB-AE. Terkmani et al. ${ }^{16}$ reported that an avidity index $\leq 3.4$ was highly predictive of AHB. A quantitative and kinetics analysis of HBsAg titer is also worth applying. In AHB, HBsAg titer disappears much faster. ${ }^{17,18}$ Various possible serological studies have been performed. A combination study of HBV DNA, HBsAg, and IgM anit-HBC quantification sought to find the best strategy to discriminate between AHB and CHB-AE. Most of the results showed that $A H B$ tends to show high IgM anti-HBC and low serum HBV DNA and HBsAg titer compared to CHB-AE. ${ }^{19}$ These findings originate from a vigorous immune response in acute viral infection.

So, do we need to go out of the way to differentiate between AHB and CHB-AE in the era of high potent antiviral agents? The KASL clinical practice guidelines for the management of CHB proposed that nucleoside analogues can be initiated in patients with severe AHB (e.g., coagulopathy, severe jaundice, liver failure). ${ }^{6}$ Other patients with $A H B$ can be free of the virus without antiviral therapy, and do not progress to chronic illness. In addition, Brahmania et al. ${ }^{20}$ reported that alanine aminotransferase (ALT) flares rarely lead to significant decompensation in CHB patients with minimal fibrosis. In this case, it might be prudent to monitor the patients, rather than treating them.

Likewise, in patients with $\mathrm{HBeAg-positive} \mathrm{or} \mathrm{HBeAg-negative}$ $\mathrm{CHB}$, prompt antiviral therapy should be initiated in the case of acute exacerbation, with the elevation of ALT $\geq 5-10$ times the upper limit of normal, and signs of liver failure such as jaundice, PT prolongation, ascites, or hepatic encephalopathy. ${ }^{6}$ Therefore, the indication of antiviral therapy is similar between the two entities. There is no urgent need to establish the criteria and additional strategies for correct classification of AHB or CHB-AE in the era of highly potent and safe antiviral agents.

However, although the amount of clinical interest is low, it would help the physician to understand the natural course of HBV to find the gold standard for better defining and differentiating AHB from CHB-AE. Hopefully, the combination of new biomarkers, such as hepatitis B core-related antigen, HBV RNA, and immunologic markers (cytokine, chemokine profiles), will lead to differential diagnosis between AHB and CHB-AE.

\section{Conflicts of Interest}

The author has no conflicts of interests to disclose.

\section{REFERENCES}

1. Lall S, Agarwala P, Kumar G, Sharma MK, Gupta E. The dilemma of differentiating between acute hepatitis $B$ and chronic hepatitis $B$ with acute exacerbation: is quantitative serology the answer? Clin Mol Hepatol 2020;26:187-195.

2. Pondé RA. Acute hepatitis B virus infection or acute exacerbation of chronic hepatitis B infection: the differential serological diagnosis. Eur J Clin Microbiol Infect Dis 2016;35:29-40.

3. European Association for the Study of the Liver. EASL 2017 clinical practice guidelines on the management of hepatitis B virus infection. J Hepatol 2017;67:370-398.

4. Sarin SK, Kumar M, Lau GK, Abbas Z, Chan HL, Chen CJ, et al. Asian-Pacific clinical practice guidelines on the management of hepatitis B: a 2015 update. Hepatol Int 2016;10:1-98.

5. Terrault NA, Lok ASF, McMahon BJ, Chang KM, Hwang JP, Jonas $M M$, et al. Update on prevention, diagnosis, and treatment of chronic hepatitis B: AASLD 2018 hepatitis B guidance. Hepatology 2018;67:1560-1599.

6. Korean Association for the Study of the Liver (KASL). KASL clinical practice guidelines for management of chronic hepatitis B. Clin Mol Hepatol 2019;25:93-159.

7. Dao DY, Hynan LS, Yuan HJ, Sanders C, Balko J, Attar N, et al. Two distinct subtypes of hepatitis $B$ virus-related acute liver failure are separable by quantitative serum immunoglobulin $\mathrm{M}$ anti-hepatitis B core antibody and hepatitis B virus DNA levels. Hepatology 2012:55:676-684.

8. Huang YW, Lin CL, Chen PJ, Lai MY, Kao JH, Chen DS. Higher cut-off 
index value of immunoglobulin $\mathrm{M}$ antibody to hepatitis $\mathrm{B}$ core antigen in Taiwanese patients with hepatitis B. J Gastroenterol Hepatol 2006;21:859-862.

9. Kumar M, Jain S, Sharma BC, Sarin SK. Differentiating acute hepatitis $B$ from the first episode of symptomatic exacerbation of chronic hepatitis B. Dig Dis Sci 2006;51:594-599.

10. Han Y, Tang Q, Zhu W, Zhang X, You L. Clinical, biochemical, immunological and virological profiles of, and differential diagnosis between, patients with acute hepatitis B and chronic hepatitis B with acute flare. J Gastroenterol Hepatol 2008;23:1728-1733.

11. Rodella A, Galli C, Terlenghi L, Perandin F, Bonfanti C, Manca N. Quantitative analysis of $\mathrm{HBsAg}$, IgM anti- $\mathrm{HBC}$ and anti-HBC avidity in acute and chronic hepatitis B. J Clin Virol 2006;37:206-212.

12. Park JW, Kwak KM, Kim SE, Jang MK, Kim DJ, Lee MS, et al. Differentiation of acute and chronic hepatitis B in IgM anti-HBC positive patients. World J Gastroenterol 2015;21:3953-3959.

13. Gerlich WH, Uy A, Lambrecht F, Thomssen R. Cutoff levels of immunoglobulin $\mathrm{M}$ antibody against viral core antigen for differentiation of acute, chronic, and past hepatitis B virus infections. J Clin Microbiol 1986;24:288-293.

14. Hong S, Lee HW, Chang DY, You S, Kim J, Park JY, et al. Antibodysecreting cells with a phenotype of Ki-67low, CD138high, CD31high, and CD38high secrete nonspecific IgM during primary hepatitis A virus infection. J Immunol 2013;191:127-134.

15. Hazell SL. Clinical utility of avidity assays. Expert Opin Med Diagn 2007;1:511-519.

16. Terkmani H, Visseaux B, Ratziu V, Poynard T, Thibault V. Anti$\mathrm{HBC}$ antibody avidity determination allows rapid discrimination between acute hepatitis $B$ and hepatitis $B$ reactivation. Hepatology 2005:42:717A-718A.

17. Frösner GG, Schomerus H, Wiedmann KH, Zachoval R, Bayerl B, Bäcker $U$, et al. Diagnostic significance of quantitative determination of hepatitis B surface antigen in acute and chronic hepatitis B infection. Eur J Clin Microbiol 1982;1:52-58.

18. Chulanov VP, Shipulin GA, Schaefer S, Gerlich WH. Kinetics of HBV DNA and HBsAg in acute hepatitis B patients with and without coinfection by other hepatitis viruses. J Med Virol 2003;69:313-323.

19. Rehermann B. Immune responses in hepatitis B virus infection. Semin Liver Dis 2003;23:21-38.

20. Brahmania M, Lombardero $M$, Hansen BE, Terrault NA, Lok AS, Perrillo RP, et al. Association between severe serum alanine aminotransferase flares and hepatitis B e antigen seroconversion and HBV DNA decrease in untreated patients with chronic HBV infection. Clin Gastroenterol Hepatol 2019;17:2541-2551.e2. 